\title{
Editorial
}

\section{La divulgación científica, un medio que permite compartir conocimiento para combatir la pandemia causada por la COVID-19}

\author{
Gloria Mercedes Díaz-Cabrera1, y Laura Stella Vega Escobar ${ }^{2}$ \\ 1 Editora, Revista TecnoLógicas, Instituto Tecnológico Metropolitano ITM, Medellín- \\ Colombia, gloriadiaz@itm.edu.co \\ ${ }^{2}$ Editora Técnica, Revista TecnoLógicas, Instituto Tecnológico Metropolitano ITM, Medellín- \\ Colombia, lauravega@itm.edu.co
}

En medio de la emergencia sanitaria generada por la pandemia de la infección por COVID19, causada por el virus SARS-CoV-2, los investigadores alrededor del mundo están trabajando fuertemente en diferentes campos de estudio, no sólo para encontrar una solución farmacológica que permita generar inmunidad o combatir efectivamente el virus, sino también para facilitar la identificación de casos positivos, mitigar el contagio y reducir sus efectos en todos los ámbitos. En este sentido, las diferentes ramas de la Ingeniería y la Tecnología aplicada juegan un papel fundamental en el desarrollo de soluciones que se puedan trasladar rápidamente de un ambiente de laboratorio a un ambiente de aplicación.

Dada la importancia de la diseminación del conocimiento científico generado, se ha incrementado notablemente la publicación de manuscritos en formato pre-impreso, tanto en plataformas dedicadas a este tipo de publicaciones, tales como ArXiv, MedRxiv, bioRxiv, entre otros [1]; como en revistas científicas arbitradas por pares [2],[3]. Esto con el fin de facilitar el acceso a los nuevos resultados de investigación, como soporte para la generación de conocimiento y la búsqueda rápida de soluciones. Incluso, esta ha sido una manera de generar red de coautorías entre grupos de instituciones, autores de diferentes países unidos en una sola búsqueda, combatir la pandemia [4].

La publicación de trabajos pre-impresos, adolece sin embargo de la garantía sobre la rigurosidad y calidad científica que se genera a través de la revisión por pares académicos. Por esta razón, revistas y editoriales, trabajan a doble marcha para revisar, editar y publicar artículos de investigación, revisiones y notas técnicas relacionadas con la COVID-19, en un tiempo record. Además, de forma generalizada se ha habilitado la publicación en acceso abierto, con el fin de garantizar el acceso a todo el contenido sin restricciones, en procura de lograr también un avance rápido en las investigaciones.

En ediciones pasadas, la revista TecnoLógicas ha presentado el papel de los avances en temas como el internet de las cosas [5], las comunicaciones digitales [6] y la ingeniería biomédica [7] para la solución a problemas de alto impacto. Hoy, estas mismas tecnologías podrían ser clave en el monitoreo, vigilancia, detección y prevención del contagio por coronavirus, así como en la mitigación del impacto en la salud de la población, la economía, la educación, entre muchos otros aspectos sociales [8-10].

En atención a la necesidad de la diseminación del conocimientos científico y tecnológico relacionados con investigaciones y desarrollos tecnológicos, que buscan contribuir a solucionar problemas generados por la COVID-19, para mitigar o combatir los efectos de la pandemia en Latinoamérica, la revista TecnoLógicas abre un espacio de divulgación de manuscritos 
en versión pre-impresa en las diferentes tipologías, es decir, artículos de investigación (cortos y completos), notas técnicas y artículos de revisión. Estos manuscritos son sometidos a una evaluación para su publicación formal en la revista, pero no han superado aún el proceso de revisión por pares académicos; sin embargo, se ponen a disposición de la comunidad, por su potencial contribución a la búsqueda de soluciones rápidas a dichos problemas. Los derechos de autor de estos manuscritos pertenecen a los autores, quienes han autorizado a la revista TecnoLógicas a realizar la publicación pre-impresa en esta sección bajo la licencia internacional CC-BY-NC-ND 4.0. Al finalizar el proceso de evaluación por pares, el manuscrito es retirado de esta sección, ya sea por ser aprobado para publicación e inclusión en un número formal de la revista, o por ser rechazado.

\section{REFERENCIAS}

[1] K. Kupferschmidt, "Preprints bring 'firehose'of outbreak data", Science, vol. 367, no. 6481, pp. 963964, 2020. https://doi.org/10.1126/science.367.6481.963

[2] E. Beldarraín-Chaple, "La información científica confiable y la COVID- 19", Revista Cubana de Información en Ciencias de la Salud, vol. 31, no. 3, pp. 1-6, 2020. URL

[3] S. Gianola, T. S. Jesus, S. Bargeri, y G. Castellini, "Publish or perish: Reporting Characteristics of Peer-reviewed publications, pre-prints and registered studies on the COVID-19 pandemic," medRxiv, Jan. 2020. https://doi.org/10.1101/2020.06.14.20130823

[4] O. Gregorio-Chaviano, C. H. Limaymanta, y E. K. López-Mesa, "Análisis bibliométrico de la producción científica latinoamericana sobre COVID-19”, biomedica, vol. 40, no. Supl. 2, may. 2020. https://doi.org/10.7705/biomedica.5571

[5] J. Botero Valencia, L. Castaño Londoño, y D. Márquez Viloria, "Avances en Internet de las Cosas", TecnoLógicas., vol. 22, no. 44, p. I-II, ene. 2019. https://doi.org/10.22430/22565337.1241

[6] E. Reyes-Vera, D. E. Senior, J. M. Luna-Rivera, y F. E. López-Giraldo, "Advances in electromagnetic applications and communications", TecnoLógicas, vol. 21, no. 43, pp. 9-13, sep. 2018. https://doi.org/10.22430/22565337.1052

[7] A. Orozco-Duque y D. Novák, "Advances in biomedical engineering: a call for enhancing empirical research”, TecnoLógicas., vol. 20, no. 40, pp. 9-11, sep. 2017.

https://doi.org/10.22430/22565337.741

[8] D. S. W. Ting, L. Carin, V. Dzau, y T. Y. Wong, "Digital technology and COVID-19," Nat. Med., vol. 26, no. 4, pp. 459-461, Apr. 2020. https://doi.org/10.1038/s41591-020-0824-5

[9] R. P. Singh, M. Javaid, A. Haleem, y R. Suman, "Internet of things (IoT) applications to fight against COVID-19 pandemic," Diabetes Metab. Syndr. Clin. Res. Rev., vol. 14, no. 4, pp. 521-524, Jul. 2020. https://doi.org/10.1016/j.dsx.2020.04.041

[10] S. Lalmuanawma, J. Hussain, y L. Chhakchhuak, "Applications of machine learning and artificial intelligence for Covid-19 (SARS-CoV-2) pandemic: A review," Chaos, Solitons \& Fractals, vol. 139, p. 110059, Oct. 2020. https://doi.org/10.1016/j.chaos.2020.110059 